\title{
Remarkable Factors in the Etiology of Monosymptomatic Enuresis Nocturna in Primary School Children
}

\author{
Tulin Oztas (Corresponding Author) \\ University of Health Sciences Gazi Yasargil Training and Research Hospital, \\ Department of Pediatric Surgery, Diyarbakir, Turkey. \\ E-mail: tulin.oztas@hotmail.com \\ Muhammet Asena \\ University of Health Sciences Gazi Yasargil Training and Research Hospital, \\ Department of Pediatric, Diyarbakir, Turkey. \\ E-mail: masena_21@hotmail.com
}

\begin{abstract}
Objective: Monosymptomatic enuresis nocturna is a common clinical problem in childhood. The aim of this study is to determine the frequency of monosymptomatic enuresis nocturna in primary school children and to evaluate related factors and families' approach to enuretic child.
\end{abstract}

Methods: A primary school was chosen in the center of Diyarbakır between January 2019 and February 2019 for a prospective cross-sectional epidemiological study. Total 535 cases aged 6-10 years included in the study. Data collection forms consisting of three parts were given to 1000 students. In the first part, age, gender, height, weight, betwetting frequency, functional constipation were evaluated. In the second part maternal education level, family economic level, the bed wetting history in the family, and the number of individuals in the family were questioned. In the third section, families' approach to enuretic child was evaluated.

Results: Frequency of monosymptomatic enuresis nocturna was $17.5 \%$. No statistically significant relationship was determined in respect of age, gender, body mass index, large family and monosymptomatic enuresis nocturna $(\mathrm{p}>0.05)$. There was a statistically significant relationship between maternal education level, family economic level, the bed wetting history in the family, functional constipation and monosymptomatic enuresis nocturna $(p<0.05) .26 .7 \%$ of families punished their children for bedwetting.

Conclusions: Prevalance of monosymptomatic enuresis nocturna were higher among the primary school children living in low socioeconomic conditions, those with mothers with a low education level, those with a positive familial history and those with constipation.

Key words: enuresis nocturna in primary school children; monosymptomatic enuresis nocturna; etiology of enuresis nocturna.

DOI: $10.7176 / \mathrm{JHMN} / 75-04$

\section{İlkokul Çocuklarında Monosemptomatik Enürezis Nokturna Etiyolojisinde Dikkat Çeken Faktörler}

Özet

Amaç: Monosemptomatik enürezis nokturna çocukluk çağında sık görülen klinik bir problemdir. Bu çalışmanın amacı ilkokul çocuklarında monosemptomatik enürezis nokturna sıklığını ve ilişkili faktörleri belirlemek ve ailelerin enürezisli çocuğa yaklaşımını değerlendirmektir.

Materyal ve metod: Prospektif kesitsel epidemiyolojik çalışma için Ocak 2019-Şubat 2019 tarihleri arasında, Diyarbakır merkezinde bir ilkokul seçildi. Çalışmaya 6-10 yaş aralığında 535 çocuk dahil edildi. Üç bölümden oluşan veri toplama formları 1000 öğrenciye dağıtıldı. İlk bölümde yaş, cinsiyet, 
boy, kilo, yatak ıslatma sıklığı, fonksiyonel kabızlık değerlendirildi. İkinci bölümde anne eğitim düzeyi, ailenin sosyoekonomik durumu, ailede yatak ıslatma öyküsü, ailedeki birey sayısı sorgulandı. Üçüncü bölümde ailelerin enürezisli çocuğa yaklaşımı değerlendirildi.

Bulgular: Monosemptomatik enürezis nokturna sıklığı \%17.5 idi. Yaş, cinsiyet, vücut kitle indeksi, geniş aile ile monosemptomatik enürezis nokturna arasında istatistiksel anlamlı ilişki saptanmadı $(\mathrm{p}>0.05)$. Anne eğitim düzeyi, ekonomik durum, pozitif aile öyküsü, fonksiyonel kabızlık ve monosemptomatik enürezis nokturna arasında istatistiksel anlamlı ilişki saptandı $(\mathrm{p}<0,05)$. Ailelerinin \%26.7'si çocuğuna ceza veriyordu.

Sonuç: Pozitif aile öyküsü olan, düşük sosyekonomik durum, düşük anne eğitim seviyesi ve fonksiyonel kabızlığı olan ilkokul çocuklarında monosemptomatik enürezis nokturna daha fazla görülmektedir.

Anahtar sözcükler: İlkokul çocuklarında enürezis nokturna; monosemptomatik enürezis nokturna; enürezis nokturna etiyolojisi,

\section{Giriş}

Yatak ıslatma çocuk cerrahisi ve çok sağlığı hekimlerinin ilkokul çağı çocuklarda çok sık karşılaştığ semptomlardan biridir. Beş yaşından büyük çocuklarda üç ay boyunca haftada en az iki kez uykuda iken yatak ıslatma ve başka bir alt üriner sistem semptomu olmaması monosemptomak enürezis nokturna (MEN) olarak adlandırılır (1). Enürezis nokturna iki şekilde sınıflandırılabilir. İdrar kontrolünün hiç sağlanamaması primer, idrar kontrolü sağlandıktan sonra en az altı ay idrar kaçırmamış fakat daha sonra tekrar yatak ıslatma ortaya çıkmış ise sekonder enürezis nokturna olarak tanımlanır $(2,3)$. Genetik faktörler, sosyoekonomik durum, anne eğitim düzeyi gibi birçok faktörün MEN gelişiminde rol oynadığ düşünülse de etiyolojisi hala tam olarak bilinmemektedir (3). MEN tedavi edilmezse çocukta özgüven eksikliği, okul başarısızlığg, iletişim güçlügüne, ailede ise endişe, duygu, davranış problemleri gibi çeşitli psikolojik ve sosyal problemlere neden olabilen önemli bir toplum sağlığ 1 sorunudur (3-5). Bu çalışmanın amacı, ilkokul çocuklarında MEN sıklığını ve ilişkili faktörleri belirlemek ve ailelerin enürezisli çocuğa yaklaşımını değerlendirmektir.

\section{Materyal ve metod}

Bu prospektif kesitsel epidemiyolojik çalışma için Ocak 2019-Şubat 2019 tarihleri arasında Diyarbakır merkezinde bir ilkokul seçildi. 6-10 yaş aralığında 1000 öğrenciye kapalı zarf içerisinde üç bölümden oluşan veri toplama formları dağıtıldı. Ailelerin formları doldurmaları istendi.

Veri toplama formunun ilk bölümünde yaş, cinsiyet, boy, kilo, yatak ıslatma sıklığı, fonksiyonel kabızlık varlığı değerlendirildi. Vücut kitle indeksi (VKİ) vücut ağırlığı $(\mathrm{kg}) /$ boy uzunluğu $(\mathrm{m})^{2}$ formülü ile hesaplandı. VKİ persentil tablosundan çocukların VKİ persentil değerleri bulundu.

Çocuklarda fonksiyonel kabızlığı değerlendirmek için Roma IV kriterleri sorgulandı. Haftada ikiden az gaita yapma, istemli olarak gaita tutma öyküsü veya gaita tutma pozisyonu, ağrıllı gaita yapma, sert gaita yapma, tuvalet deliğini tıkayacak kadar kalın gaita yapma, haftada en az bir kez gaita inkontinansı sorguland1. İlaç kullanmadan yumuşak dışkı yapma, dışkılama ile ilişkili, dışkılama sıklığg veya dışk1 şeklinde değişme ile ilişkili karın ağrısı olup olmadığı sorgulandı. En az bir ay süre ile haftada en az bir kez bu kriterlerden en az ikisine sahip olan çocuklar fonksiyonel kabız olarak değerlendirildi (6).

İkinci bölümde anne eğitim düzeyi, ailenin sosyoekonomik durumu, ailede yatak sslatma öyküsü, ailedeki birey sayısı sorgulandı. Ailenin ekonomik durumu 2019 yılı asgari ücreti göz önünde bulundurularak üç kategoride değerlendirildi. Aylık gelir asgari ücret veya asgari ücretin iki buçuk katı düşük, asgari ücretin 2,5- 5 katı orta ve asgari ücretin beş katından fazla ise iyi ekonomik durum olarak değerlendirildi (7). Aile beş kişiden az ise küçük, beş veya daha fazla kişiden oluşuyorsa geniş aile olarak değerlendirildi (4).

Üçüncü bölümde ailenin enürezisli çocuğa yaklaşımı: tedavi için doktora götürmek (1), ceza vermek (2), herhangi bir müdahalede bulunmamak (3) olmak üzere üç kategoride değerlendirildi

Tekrarlayan idrar yolu enfeksiyonu öyküsü, diabetes mellitus, nörolojik, psikiyatrik hastalığı olan, anüs veya genitoüriner cerrahi geçirmiş olan çocuklar çalışmaya dahil edilmedi.

Bu çalışma Sağlık Bilimleri Üniversitesi Diyarbakır Gazi Yaşargil Eğitim ve Araştırma Hastanesi Klinik Çalışmalar Etik Kurulu tarafından onaylandı (25.01.2019/ No:217) .

\section{3.İstatiksel yöntem}

Çalışmada elde edilen veriler SPSS Statistics for Windows, Version 22.0. (IBM Corp. Released 2013. Armonk, NY) paket programı kullanılarak istatistiksel olarak analiz edildi. Kategorik değişkenler sayı

27 I $P$ a g e

www.iiste.org 
(n) ve yüzde (\%) olarak ifade edildi ve sürekli verilerin normal dağılımını incelemek için KolmogorovSmirnov testi kullanıldı. Normal dağılım gösteren sayısal değişkenler ortalama \pm standart sapma olarak gösterildi. Normal olarak dağılmış sayısal değişkenler Student's T testi kullanılarak karşılaştırıldı. Kategorik değişkenler açısından fark olup olmadığını belirlemek için Pearson Ki- kare Testi kullanıldı. Tüm verilerde $\mathrm{p}<0.05$ istatistiksel olarak anlamlı kabul edildi.

\section{Bulgular}

Veri toplama formlarının 558'i aileler tarafından dolduruldu. Endokrin, nörolojik veya psikiyatrik hastalığı olan $(n=9)$, anüs veya genitoüriner cerrahi geçiren $(n=6)$, tekrarlayan idrar yolu enfeksiyonu $(n=7)$ öyküsü olan, veri toplama formunda bilgi eksikliği $(n=1)$ olan 23 çocuk çalışma dışı bırakıldı. Tablo 1'de MEN ve MEN olmayan çocukların sosyodemografik verilerinin dağılımı sunulmuştur. Çalışmaya dahil edilen 535 çocuğun 290’’ (\%54.2) kı, 245’i (\%45.8) erkek ve yaş ortalaması 7.6 $\pm 1,1$ yıl idi (6-10 y1l).

Tablo 1 Çalışmaya katılan çocukların sosyodemografik özelliklerinin dağılımı

\begin{tabular}{|c|c|c|c|}
\hline Değişkenler & MEN & MEN olmayan çocuk & $\mathrm{P}$ \\
\hline & $(n=94)$ & $(n=441)$ & \\
\hline & $\mathrm{n}(\%)$ & $\mathrm{n}(\%)$ & \\
\hline Ortalama Yaş (yıl) & $7.7 \pm 0.7(6-10)$ & $7.6 \pm 1.1(6-10)$ & 0.349 \\
\hline Cinsiyet & & & 0.859 \\
\hline $\mathrm{K} 1 \mathrm{z}$ & $54(57.4)$ & $236(53.5)$ & \\
\hline Erkek & $40(42.5)$ & $205(46.4)$ & \\
\hline VKİ(kg/m²) & & & 0.114 \\
\hline$<5$ persentil & $6(6.4)$ & $52(11.8)$ & \\
\hline 5-95 persentil & $77(81.9)$ & $363(82.3)$ & \\
\hline$>95$ persentil & $11(11.7)$ & $26(5.9)$ & \\
\hline Kabızlık & & & 0.001 \\
\hline Evet & $33(35.1)$ & $98(22.2)$ & \\
\hline Hayır & $61(64.8)$ & $343(77.7)$ & \\
\hline Aile yapısı & & & 0.325 \\
\hline Geniş & $69(73.4)$ & $303(68.7)$ & \\
\hline Küçük & $25(26.5)$ & $138(31.2$ & \\
\hline Anne eğitim düzeyi & & & 0.001 \\
\hline İlkokul & $52(55.3)$ & $180(40.8)$ & \\
\hline Ortaokul & $24(25.5)$ & $89(20.1)$ & \\
\hline Lise & $12(12.7)$ & $94(21.3)$ & \\
\hline Üniversite & $6(6.3)$ & $77(17.4)$ & \\
\hline Ekonomik durum & & & 0.001 \\
\hline Düşük & $35(43.5)$ & 191(43.3) & \\
\hline Orta & $51(54.2)$ & $213(48.2)$ & \\
\hline Yüksek & $3(3.1)$ & $42(9.5)$ & \\
\hline Pozitif aile öyküsü & & & 0.001 \\
\hline Evet & $34(36.2)$ & $49(11.2)$ & \\
\hline Hayır & $60(63.8)$ & $392(88.8)$ & \\
\hline
\end{tabular}

MEN: Monosemptomatik enürezis nokturna

VKI: Vücut kitle indeksi

Çalışmamızda MEN sıklığ $1 \% 17.5$ olup, olguların 54'ü kız ve 40’’ erkekti. MEN ile cinsiyet arasında istatistiksel anlamlı ilişki saptanmadı $(\mathrm{p}=0.859)$. MEN'li çocukların yaş ortalaması $7.7 \pm 1,3$ yıl idi $(6-10$ y1l). MEN ile yaş arasında istatistiksel anlamlı ilişki saptanmadı $(\mathrm{p}=0,349)$. Yaşa ve cinsiyete göre MEN sıklığg Tablo 2’de, çalışmaya katılan çocuklarda yatak ıslatma sıklığg Tablo 3'de sunuldu. 
Tablo 2. Yaşa ve cinsiyete göre monosemptomatik enürezis nokturna sıklığ1

\begin{tabular}{ccccccc}
\hline Yaş (yıl) & \multicolumn{2}{c}{ Kız } & \multicolumn{2}{c}{ Erkek } & \multicolumn{2}{c}{ Toplam } \\
\cline { 2 - 7 } & $\mathbf{n}$ & $\mathbf{\%}$ & $\mathbf{n}$ & $\mathbf{\%}$ & $\mathbf{n}$ & \% \\
$\mathbf{6}$ & 1 & 1.06 & 2 & 2.12 & 3 & 3.19 \\
$\mathbf{7}$ & 16 & 17.02 & 14 & 14.90 & 30 & 31.91 \\
$\mathbf{8}$ & 23 & 24.47 & 22 & 23.40 & 45 & 47.87 \\
$\mathbf{9}$ & 9 & 9.58 & 6 & 6.39 & 15 & 15.95 \\
$\mathbf{1 0}$ & 1 & 1.06 & 0 & 0 & 1 & 1.06 \\
\hline Total & 50 & 53.19 & 44 & 46.81 & 94 & 100 \\
\hline
\end{tabular}

Tablo 3. Çalışmaya katılan çocukların yatak ıslatma sıklığı

\begin{tabular}{lcc}
\hline & \multicolumn{2}{c}{ Yatak sslatma sıklı̆̆ı } \\
\cline { 2 - 3 } & $\mathbf{n}$ & $\boldsymbol{\%}$ \\
\hline Ayda bir & 56 & 10.46 \\
\hline İki haftada bir & 9 & 1.68 \\
\hline Haftada bir & 49 & 9.15 \\
\hline Haftada iki & 51 & 9.53 \\
\hline Her gün & 43 & 8.03 \\
\hline Toplam & 208 & 38.85 \\
\hline
\end{tabular}

MEN'li çocukların ortalama vücut kitle indeksi (VKİ) $16.3 \pm 2.4$ kg/m² $\left(11-25 \mathrm{~kg} / \mathrm{m}^{2}\right)$ olup, \%6.4'ünde VKİ $<5$ persentil, \%81.9'unda VKİ 5-95 persentil aralığında, \%11.7'sinde VKİ >95 persentil idi. MEN ile VKİ arasında istatistiksel anlamlı ilişki saptanmadı $(\mathrm{P}=0.114)$. MEN'li çocukların \%35.1'inde fonksiyonel kabızlık vardı. MEN ile fonksiyonel kabızlık arasında istatistiksel anlamlı ilişki saptandı $(\mathrm{p}=0.01)$.

MEN'li çocukların \%73.4'ü geniş ailede yaşıyordu. Geniş aile yapısı ile MEN arasında istatistiksel anlamlı ilişki saptanmadı ( $\mathrm{p}=0.325)$. MEN'li çocukların annelerinin \%55.3'ü ilkokul, \%25.5'i ortaokul, \%12.7'si lise ve \%6.3'ü üniversite mezunuydu. Anne eğitim düzeyi ve MEN arasında istatistiksel anlamlı ilişki vardı $(\mathrm{p}=0,01)$. Enürezisli çocukların ailelerinin \%3.1'i iyi, \%54.2'si orta ve \%43.5'i düşük ekonomik gelir düzeyine sahipti. Ailelerin ekonomik düzeyi ile MEN arasında istatistiksel anlamlı ilişki saptandı $(\mathrm{p}=0.01)$. MEN' li çocukların \%36.2'sinde pozitif aile öyküsü vard1, \%30.8'inin babasında, \%5.3'nün annesinde MEN olduğu belirlendi. MEN ile pozitif aile öyküsü arasında anlamlı ilişki saptandı $(\mathrm{p}=0.01)$.

Çalışmamızda MEN'li çocukların ailelerinin \%37.8'sinin tedavi için çocuklarını doktora götürdüğü, \%26.7'sinin ceza verdiği, \%35.5'nin ise herhangi bir müdahalede bulunmadı̆̆ saptandı.

\section{Tartışma}

İlkokul çağı çocuklarında yaygın bir klinik problem olan MEN'nin cinsiyet, yaş, etnik köken, kültür ve tanı kriterlerine bağlı olarak farklı oranlarda görüldüğü bildirilmiştir (8). Beş yaşından büyük çocuklarda \%10-30 arasında MEN görüldüğü ve yaş ilerledikçe MEN sılığının azaldığı bildirilmiştir (9-11). Çalışmamızda 6-10 yaş aralığında MEN sıklığı \%17.5 olup literatürle uyumlu idi. Çalışmamızın sonuçları yaş arttıkça işeme kontrolünün geliştiğini ve MEN'nin daha az oranda görüldüğünü desteklemektedir.

Cinsiyet MEN ile ilişkili olabileceği düşünülen faktörlerden biridir. MEN'nin maturasyonun daha yavaş olması nedeni ile erkek çocuklarda daha sık görüldüğ̈̈ bildirilirken (1,9,12-14), çalışmamızda olduğu gibi MEN ile cinsiyet arasında ilişki olmadığını bildiren çalışmalar da vardır $(3,10,15)$.

VKİ MEN etiyolojisinde rolü olduğu düşünülen bir diğer faktördür. Obez çocuklarda sıklıkla eşlik eden obstrüktif uyku apnesi, fonksiyonel mesane kapasitesini etkileyen sağlıksız yiyecekleri tüketilmesi, kişilik/davranış özelliklerindeki farklılıklar nedeni ile daha fazla MEN görüldüğü belirtilmiştir $(16,17)$. 
Boryri ve ark yaptığı çalışmada enürezisli çocukların daha düşük VKİ olduğu bildirilirken (13), çalışmamızda olduğu gibi MEN ile VKİ arasında bir ilişki olmadığını bildiren çalışmalar vardır $(2,12)$. MEN ile ilişkili olduğu düşünülen faktörlerden biride fonksiyonel kabızlıktır. MEN li çocukların \%1530’unda fonksiyonel kabızlık görüldüğü raporlanırken (15), Sarıcı ve ark. yaptığı çalışmada fonksiyonel kabızlığın MEN ile ilişkili olmadığı belirtilmiştir (12). Kabız çocuklarda dolu rektumun mesaneye bası yaptığı, mesane kapasitesini azaltarak, detrusör instabilitesini artırdığı, kolonun hareketine bağlı olarak detrusor instabilitesinin geceleri daha fazla olduğu raporlanmıştır (18). Çalışmamızın sonuçları fonksiyonel kabızlığı olan çocuklarda MEN'nin daha fazla görüldüğünü ve çocuklara tuvalet eğitiminin verilmesi, kabızlık tedavisinin başlanması ile MEN sıklığında azalma olacağını düşündürmektedir.

MEN'nin kalabalık ve çok çocuklu ailelerde daha sık görüldüğü belirtilmiştir (4,8,11). Sarıcı ve ark çalışmada çalışmamızda olduğu gibi ailedeki birey sayısı ile MEN arasında ilişki olmadığı belirtilmiştir (12). Ebeveyn eğitim düzeyinin MEN etiyolojisinde rol oynayabileceği düşünülmüştür. Anne eğitim seviyesi azaldıkça çalışmamızdaki gibi MEN sıklığının arttı̆̆ı raporlanmıştır $(3,5,8)$. Ailenin sosyoekonomik düzeyi MEN sıklığı ile ilişkili olduğu düşünülen faktörlerden biridir. Çalışmamızdaki gibi düşük sosyoeonomik düzeyli ailelerde MEN'nin daha sık görüldüğü belirtilirken (3,5,8,9,19-21), Imoudu ve ark yaptığı çalışmada MEN ile ailenin ekonomik durumu arasında istatistiksel anlamlı bir ilişki olmadığı raporlanmıştır (1). Çalışmamızın sonuçları ailenin eğitim ve sosyoekonomik düzeyi ile ilişkili olan tuvalet eğitimi, kültürel ve çevresel faktörlerin MEN gelişimine katkıda bulunabileceğini düşündürmektedir.

Pozitif aile öyküsü olanlarda MEN'nin daha sık görüldüğü ve kalıtımın etiyolojide rolü olduğu düşünülmektedir. MEN'nin otozomal dominant geçtiği ve 8,12,13 nolu kromozomların enürezisle ilişkili olabileceği bildirilmiştir (10). Yapılan çalışmalarda enürezisli çocukların \%22-66'sında ailede yatak 1slatma öyküsü olduğu bildirilmiştir $(1,3,4,8,10-12,14,20)$. Çalışmamızda MEN'li çocuklarda pozitif aile öyküsü \%36.2 olup literatürle uyumlu idi. Çalışmamızın sonuçları da MEN'nin kalıtsal bir geçiş olduğunu ve enüretik ebeveynlerin çocuklarının yakın takip gerektirdiğini, bu olgularda erken tedavi başlanması ile çocuğun ve ailenin yaşam kalitesinin artacağını düşündürmektedir.

MEN'li çocuğa yaklaşımın ebeveyn eğitim ve farkındalık düzeyi ile değiştiği, enüretik çocukların \%62'sinin aileleri tarafından cezalandırıldığı bildirilmiştir (16). Mohammed ve ark. yaptığı çalışmada ise MEN'li çocuklara \%24.3oranında ceza verildiği ve sadece \%6'sının profesyonel destek aldığ raporlanmıştır (15). Çalışmamızın sonuçları ailelerin MEN'nin yarattığı okul başarısızlığı, sosyal izolasyon ve duygusal stresin farkında olmadığını ve bu nedenle tıbbı tedavi oranının düşük (\%37.8) olduğunu göstermiştir. Yapılacak eğitimler ile ailelerin MEN ve olası etkileri konusunda farkındalığın artırılması ile çocukların ceza verilmesi büyük oranda engellenebilir ve tıbbi destek alma oranı artırilabilir.

Çalışmamızın kısıtlayıcı yönleri çalışmanın bir okulda yapılmış olması, primer ve sekonder ayrımı yapılmadan tüm MEN'li çocukların çalışmaya dahil edilmesidir.

\section{Sonuç}

MEN aile öyküsü pozitif olan, sosyoekonomik durumu düşük, anne eğitim seviyesi düşük ve fonksiyonel kabızlığı olan ilkokul çağı çocuklarda daha sık görülmektedir. Çocuğun ve ailesinin yaşam kalitesini önemli ölçüde olumsuz etkileyen bu sorunun azaltılması için ailelerin bilinçlendirilmesinde sağlık çalışanlarına büyük sorumluluklar düşmektedir. Okul yöneticileri ve öğretmenlerle işbirliği yapılması MEN'li çocukların yaşadığg psikolojik ve sosyal sorunların azalmasında büyük rol oynayacaktır.

\section{Kaynaklar}

1 Imoudu IA, Bugaje MA, Aikhionbare HA. Childhood Enuresis: A study of Dogarawa Community of North Western Nigeria. J Dental \& Med Sci. 2014;13(4):06-10.

2 Monkhouse K, Caldwell PH, Barnes EH. The relationship between urinary incontinence and obesity in childhood. J Paediatr Child Health 2019;55(6):625-631.

3 Alkot M, Deeb M. Nocturnal Enuresis among School Children in Menofia Governorate, Egypt; a Hidden Problem. Journal of American Science, 2012;8(1):327-334.

4 Hashem M, Morteza A, Mohammad K, Ahmad-Ali N. Prevalence of Nocturnal Enuresis in School Aged Children The Role of Personal and Parents Related Socio-Economic and Educational Factors. Iran J Pediatr. 2013;23 (1): 59-64. 
5 Solanki AN, Desai SG. Prevalence and risk factors of nocturnal enuresis among school age children in rural areas. Int J Res Med Sci. 2014;2(1):1-4

6 Levy EI, Lemmens R, Vandenplas Y, Devreker T. Functional constipation in children: challenges and solutions. Pediatric Health, Medicine and Therapeutics 2017; 8: 19-27.

7 Inan M, Aydiner CY, Tokuc B, Ayvaz S, Ayhan S, Ceylan T, et al. Factors associated with childhood constipation. J Paediatr Child Health. 2007; 43(10): 700-706.

8 Doganer YC, Aydogan U, Ongel K, Sari O, Koc B, Saglam K. The Prevalence and Sociodemographic Risk Factors of Enuresis Nocturna among Elementary School-age Children. J Family Med Prim Care. 2015; 4(1): 39-44.

9 Ozkan S, Durukan E, Iseri E, Gurocak S, Maral I, Bumin M.A. Prevalence and risk factors of monosymptomatic nocturnal enuresis in Turkish children. Indian J Urol. 2010; 26(2): 200-205.

10 Aloni MN, Ekila MB, Ekulu PM, Aloni ML, Magoga K. Nocturnal Enuresis in Children in Kinshasa, Democratic Republic of Congo. Acta Paediatr. 2012;101(10):e475-478.

11 Aljefri HM, Basurreh OA, Yunus F, Bawazir AA. Nocturnal enuresis among primary school children. Saudi J Kidney Dis Transpl. 2013;24(6):1233-1241.

12 Sarici H, Telli O, Ozgur BC, Demirbas A, Ozgur S, Karagoz MA. Prevalence ofnocturnal enuresis and its influence on quality of life in school-aged children. J Pediatr Urol. 2016;12(3):159.e1-6.

13 Boryri T, Noori NM, TeimouriA. Association between enuresis and body mass index in schoolchildren. Int J Pediatr. 2016 ;4(12):3969-3976.

14 Shah S, Jafri RZ, Mobin K, Mirza R, Nanji K, Jahangir F, et al. Frequency and features of nocturnal enuresis in Pakistani children aged 5 to 16 years based on ICCS criteria: a multi-center cross-sectionalstudy from Karachi, Pakistan. BMC Fam Pract. 2018;19(1):198.

15 Mohammed AH, Saleh AG, Al Zoheiry I. Frequency of bedwetting among primaryschool children in Benha city, Egypt. Egypt J Med Hum Genet. 2014;15(3):287-92.

16 Taha AZ, Sabra AA. Nocturnal enuresis at a primary health care setting: analysis of 117 cases. Bahrain Med Bull. 2011; 33(2): 78-82.

17 Ma Y, Shen Y, Liu X. Original Article Functional constipation and bladder capacity and severity of enuresis in children: a correlation study. Int J Clin Exp Med. 2018;11(2):806-811.

18 Hsiao YC, Wang JH, Chang CL, Hsieh CJ, Chen MC. Association between constipation and childhood nocturnal enuresis in Taiwan: a population-based matched case-control study. BMC Pediatr 2020; 20(1):35

19 Zahra SS. A prospective longitudinal study to estimate the prevalence of obesity in Egyptian children with nocturnal enuresis and the association between body mass index and response to therapy. Egypt J Med Hum Genet. 2017;18(3):211-218.

20 Yanaral F, Eroglu A, Cilesiz NC, Gezmis CT, Tandogdu Z, Balci C, et al. Evaluation of etiological risk Factors of primary monosymptomatic enuresis. JAREM. 2019; 9(3):102-106.

21 Tekin M, Celik V, Almıs H, Konca C, Bucak IH, Ercan S, et al. The Evaluation of patients diagnosed with monosymptomatic nocturnal enuresis. J Pediatr Res 2015;2(3):140-3. 